\title{
ENFOQUE SOBRE EL MUNDO JURÍDICO. CONSTITUCIÓN Y DERECHOS FUNDAMENTALES
}

\author{
Raúl Gustavo Ferreyra ${ }^{1}$
}

El Derecho procede directamente de la naturaleza humana.

Las constituciones modernas configuran un ejemplo cabal de sistemas jurídicos técnicamente desarrollados. Los derechos fundamentales descritos en la Constitución federal de la Argentina constituyen líneas de acción profundamente significativas. Fijan límites y vínculos insuperables para el uso de la fuerza del Estado.

Consecuentemente, del mismo modo que el lenguaje se rige por la gramática, la arquitectura por el espacio, el empleo de la fuerza del Estado se debe regir por los derechos fundamentales alojados en las constituciones.

\section{$\$$ I. PUNTO DE PARTIDA}

El Derecho es una creación del hombre.

Las reglas o normas de Derecho siempre regulan o determinan, directa o indirectamente, la conducta del hombre. El Derecho positivo, pues, fruto del arbitrio humano, es un ente o cosa variable, mudable, susceptible de cambio ${ }^{2}$.

Conocer objetivamente cualquier sistema jurídico significa elaborar argumentos en forma de proposiciones. El saber jurídico debe demarcar y distinguir los entes que abarca y los que quedan excluidos ${ }^{3}$; la configuración del concepto Derecho determina decisivamente qué ha de comprenderse en su estudio científico. La función de conocimiento del sistema jurídico siempre posibilita tres tipos de comentarios o enfrenta igual cantidad de problemas ${ }^{4}$.

\footnotetext{
${ }^{1}$ Doctor en Derecho por la Universidad de Buenos Aires. Catedrático de Derecho Constitucional, Facultad de Derecho, Universidad de Buenos Aires.

${ }^{2}$ Kelsen, Hans, "La doctrina del Derecho natural y el positivismo jurídico", traducción de Eugenio Bulygin, en Academia. Revista sobre enseñanza del Derecho, año 6, número 12, Departamento de Publicaciones de la Facultad de Derecho de la Universidad de Buenos Aires, Buenos Aires, 2008, p. 184.

${ }^{3}$ Zaffaroni, Eugenio Raúl et al., Derecho Penal, Ediar, Buenos Aires, 2000, p. 3.

${ }^{4}$ Bobbio, Norberto, Teoría General del Derecho, Temis, Bogotá, 1997, pp. 20 y ss.
} 
Véase.

Uno: La congruencia o incongruencia de las reglas que lo integran con valores superiores que inspiran determinado ideal de justicia. En estos casos, los planteos giran en torno a los fundamentos axiológicos del sistema jurídico, en virtud que la justicia o injusticia de un sistema normativo equivale a plantear el problema de la correspondencia entre lo que la realidad ofrece y determinada idealidad sugiere.

Dos: Sobre la estructura de las reglas que integran el sistema; en este caso, el problema se relaciona con la existencia y configuración misma de las reglas de Derecho. Desde este enfoque, puede decirse que se emprende el examen de los problemas ontológicos del Derecho.

Tres: En este ámbito la preocupación central consiste en el análisis de los problemas que se derivan de si las reglas que los componen son o no son efectivamente cumplidas y acatadas por las personas y órganos a quienes se dirigen y, en caso de producirse transgresiones a sus prescripciones, cómo ellos son hechos valer (por medio de la coerción) por la autoridad que los impuso. En este caso, la gama de los problemas aparece relacionada con la eficacia de las reglas jurídicas que integran un sistema normativo; remite, pues, al examen de los problemas sociológicos del Derecho.

El enfoque ontológico o estructural predomina en esta contribución y constituye la determinación conceptual del objeto de estudio. Decir, pues, que el Derecho disciplina la arquitectura y el control social, al determinar la conducta de los ciudadanos y los poderes, implica admitir su normatividad como propiedad relevante. El Derecho es un sistema complejo, compuesto básicamente ${ }^{5}$ de reglas sobre la planificación, la organización y la aplicación de la fuerza cuya expresión o manifestación se materializa por intermedio del discurso elaborado por los poderes estatales ${ }^{6}$. Es en este contexto en el cual puede verificarse la afirmación cuyo

\footnotetext{
${ }^{5}$ Bulygin, Eugenio, "Sobre el problema de la objetividad del Derecho", en AA.VV., Las razones de la producción del Derecho. Argumentación constitucional, argumentación parlamentaria y argumentación en la selección de jueces, coordinadores Nancy Cardinaux, Laura Clérico y Aníbal D’Auria, Departamento de Publicaciones de la Facultad de Derecho, UBA, 2006, Buenos Aires, p. 40.

${ }^{6}$ Respecto del tema lenguaje y derecho, es decir, la/s forma/s que puede (paradigmáticamente) asumir la manifestación de este último, v., por ejemplo, (i) AlChourrón, Carlos E. y BulYgin. Eugenio: no parece controvertible que las normas son expresables en el lenguaje, es decir, por medio de enunciados (Introducción a la metodología de las ciencias jurídicas y sociales, Astrea, Buenos Aires, 1992, p. 99); (ii) CARRIó, Genaro: las normas jurídicas están compuestas por palabras que tienen las características propias de los lenguajes naturales. No se trata de una circunstancia meramente accidental; tampoco debe ser vista como un defecto grave ni como una insuficiencia remediable de la técnica de control social que se denomina "Derecho". Por ello, es legítimo decir que las normas jurídicas no sólo se valen del lenguaje natural, sino que, en cierto sentido, tienen que hacerlo (Notas sobre derecho y lenguaje, Abeledo-Perrot, Buenos Aires, 1994, p. 47).
} 
enunciado sostiene que esta programación del ejercicio del poder, racionalmente planificada, que realiza el Derecho, puede ser conceptuada como la razón de la fuerza.

¿Razón de la fuerza?7 Sí, razón de la fuerza, que quiere significar, sencillamente, que el Derecho muestra o pretende mostrar cómo sus reglas organizan y programan el ejercicio que el poder estatal decide llevar a cabo. Nada más.

¿Ustedes dirán que la verificación de estos contenidos puede dar lugar a injusticias? No hay dudas. ¿Que por intermedio de ello puede aducirse que el Derecho sería sólo la expresión de los más fuertes y no de los más justos? Tampoco tengo mayores dudas al respecto. Ni de la alarma comunitaria que ello fundadamente provoca.

El planteo teórico que aquí se desarrolla (ver, especialmente, ut infra sección IX) consiste en un esquema de análisis de la complejidad que presenta el Derecho que, sin compadecerse por completo con ninguna de las versiones que se reportan desde el positivismo jurídico, se identifica con una interpretación preferente de los derechos fundamentales de rango y jerarquía constitucional. ¿Cómo es esto? Se propugna la posibilidad de que los derechos fundamentales alojados en los textos constitucionales sirvan como efectivas líneas de acción para el empleo de la fuerza estatal, configurando o reforzando, según los casos, los caminos en los cuales cada uno de los ciudadanos que componen la sociedad pueda elegir y decidir libre, individual, grupal y/o colectivamente, y en igualdad de oportunidades, la orientación de los planes de su vida.

El itinerario, y sin que ello signifique anticipar las conclusiones, puede ser descripto en las dos proposiciones que siguen: el derecho es la razón de la fuerza, entendida la palabra "razón" tanto como (a) descripción (y legalidad) de la coacción, cuanto como de su (b) argumentación racional ${ }^{8}$. En ambos supuestos, el

\footnotetext{
${ }^{7}$ El término "razón", de acuerdo con las definiciones lexicográficas que suministra el DRAE, tiene más de quince acepciones. En este contexto -es decir, el que se anota en texto principal-, el término es empleado en un sentido "débil" (a) tanto como dando noticia o informando (por intermedio del lenguaje) acerca de la organización de la fuerza; o más bien, (b) empleando, por ej., específicamente algunas de sus acepciones (la tercera): "palabras o frases con que se expresa el discurso" o (la sexta): "orden y método en una cosa"; (c) agregando y adelantando por mi parte: del poder del Estado. El significado de la expresión "razón de la fuerza" describe, dentro de este perímetro, que el Derecho expresa el discurso del poder y/o que el Derecho es quien organiza el uso de la coacción estatal. ¿¡Fuerza? Intervención o amenaza de intervención enfilada a la creación y/o mantenimiento de un sistema jurídico, en la orientación deseada por quienes ejercen o detentan el poder.

${ }^{8}$ Sobre las funciones de argumentación y descripción, ver, por ej.: Popper, Karl, "Conocimiento: subjetivo contra objetivo", en Escritos selectos, compilador David Miller, Fondo de Cultura Económica, México, 1995, pp. 61-82.
} 
conocimiento objetivo del Derecho 9 es la finalidad buscada, es decir, la definición de su identidad y los rasgos básicos de su alcance.

\section{§ II. LA DEFINICIÓN DEL DeREChO}

Si un humanista del prestigio de Norberto Bobbio ha llegado a sostener que para cultivar un campo tan inmenso como resulta el Derecho se requiere un potente tractor, mientras que el único instrumento que él había llegado a poseer eran las tijeras de un jardinero, mis ambiciones no pueden ser sino más modestas, y descreo que los resultados de la tarea puedan servir de pan para los dientes de quienes concentran sus afanes en el estudio de los problemas de la teoría general del Derecho ${ }^{10}$. No obstante, constituye proposición capital la consideración del Derecho como un artificio, en la misma línea del significado que le atribuyera Juan Jacobo Rousseau ${ }^{11}$. El Derecho es una realización cultural ${ }^{12}$, es decir, resultado de la actividad del hombre. Sin embargo, la historia exhibe que los seres humanos, muchas veces, han probado que la irracionalidad, tanto en la producción como en la realización del Derecho, demuestra que el hombre puede construir la cultura y también destruirla.

La definición del Derecho ha causado, ocasiona y seguramente seguirá provocando escozor, polémica, desconcierto, dificultades, perplejidades. Y la lista de efectos puede continuar.

Preguntarse qué es el Derecho comprende una situación sumamente vaga y ambigua. Si sólo se focaliza la atención en la producción del saber jurídico del siglo XX, las respuestas que se encontrarán son disímiles y contradictorias. Por ejemplo, Herbert Hart sostuvo en el año 1961 que no hay una vasta literatura

\footnotetext{
9 Barbarosch, Eduardo, "La objetividad en la moral y en el Derecho", en Ideas y Derecho, Anuario de la Asociación Argentina de Filosofía del Derecho, Año 5, número 5, Rubinzal Culzoni, Buenos Aires, 2005, pp. 85-102.

${ }^{10}$ Boвbio, Norberto, Contribución a la teoría del Derecho, traducción de Alfonso Ruiz Manero, Torres Editor, Valencia, 1980, p. 12.

${ }^{11}$ Afirma Rousseau: "puesto que ningún hombre tiene una autoridad natural sobre sus semejantes, y puesto que la naturaleza no produce ningún derecho, sólo quedan las convenciones como único fundamento de toda autoridad legítima entre los hombres... El pacto fundamental sustituye con una igualdad moral y legitima lo que la naturaleza había podido poner de desigualdad física entre los hombres, y que, pudiendo ser desiguales en fuerza o talento, se convierten en iguales por convención y derecho" (El contrato social, Altaya, Barcelona, 1993, pp. 8 y 23).

${ }_{12}$ Maier, Julio, Derecho Procesal Penal, Fundamentos, tomo I, "El orden jurídico", Editores del Puerto, Buenos Aires, 2004, p. 6. En igual sentido, ver: HÄBERle, Peter, "La constitución como cultura”, en Anuario Iberoamericano de Justicia Constitucional, traducción de Francisco Fernández Segado, número 6, Madrid, 2002, pp. 177-198.
} 
para contestar las preguntas “¿qué es medicina?” o “¿qué es química?”, como sí la hay para contestar la pregunta “¿qué es Derecho?”. ${ }^{13}$

Palabras que integran el lenguaje tienen importante pluralidad de significados. La polisemia del término Derecho tiene grado superlativo. Si se renuncia de antemano a la búsqueda de definiciones dirigidas a la estipulación de sus propiedades esenciales y naturales, se encuentra que Derecho, convencionalmente, tiene varios significados, tanto en el lenguaje de los juristas como en el caso del lenguaje de las fuentes jurídicas. En el caso del lenguaje que emplean los juristas, básica y precariamente se pueden distinguir no menos de dos orientaciones, las cuales se encuentran estrechamente ligadas entre sí.

En una primera significación, "Derecho" (objetivo) se emplea para designar a un sistema u ordenamiento jurídico, o conjunto de normas jurídicas vigentes en determinado espacio y tiempo; o combinación ${ }^{14}$ de normas primarias, secundarias y otros enunciados no normativos.

Una segunda significación del término alude al Derecho no como sistema u ordenamiento, sino como el nombre que recibe la disciplina científica o saber o ideología cuyo objeto -mediante la utilización de herramientas provenientes de los campos lógicos y/o empíricos y/o valorativos- es la identificación y/o sistematización y/o valoración de la compleja realidad configurada a partir del "Derecho objetivo". Es decir, que tanto el estudio del objeto como el objeto del estudio reciben el mismo apodo. Para toda significación se utiliza el mismo signo o símbolo: Derecho.

Puede agregarse otro significado: derecho entendido como facultad, pretensión o expectativa subjetiva o grupal. Lógicamente, si bien no es un escollo insalvable, se debe lamentar que la polisemia apuntada no favorece precisamente las indagaciones ni las reflexiones del saber jurídico.

De los significados del término Derecho, el que se tiene en foco como cabecera de análisis es el de Derecho como sistema jurídico. Dicho sea de paso, la delimitación de por sí no da por ganada la partida ni asegura su resultado. Sólo ayuda a esparcir las piezas en el tablero, decidiendo ulteriores realizaciones. Nada más. Porque la delineación del perímetro del primero de los significados del término Derecho, aun si lo entendiera de manera muy imprecisa,

\footnotetext{
${ }^{13}$ Hart, Herbert, El concepto de Derecho, traducción de Genaro Carrió, Abeledo Perrot, Buenos Aires, 1992, p. 1. Inevitablemente, debe entenderse que el momento de la aludida indagación fue el de la publicación de la versión inglesa de la obra citada.

${ }^{14}$ Julio Maier describe al Derecho como la combinación de reglas entre las que se encuentran normas de deber, normas potestativas y reglas permisivas específicas. V. MAIER, Julio B. J., "I. El orden jurídico", en Derecho procesal penal. Fundamentos, tomo I. A, Hammurabi, Buenos Aires, 1989, pp. 94-95.
} 
simplificada y liviana como combinación de normas, no dista de ser altamente problemática.

Con rigor se señala que los sistemas jurídicos designan un macroconjunto de normas jurídicas cuyos componentes son todos reconducibles a un fundamento común de validez: típicamente una constitución. La admisión de que el Derecho es un sistema puede ser entendida en no menos de dos sentidos: (a) asumir que el Derecho es un sistema supone admitir que el Derecho manda y pone orden; (b) por otra parte, al asumir que el Derecho es un sistema se pretende decir que el Derecho es algo ordenado, coherente y quizá tendencialmente completo ${ }^{15}$. En los desarrollos que siguen, al Derecho se le caracteriza -la mayoría de las veces, de modo implícito- como un sistema que intenta poner orden, o que sus mandas reglamentan el uso de la coerción.

Significa admitir, además, al reconocer en el Derecho a un sistema, que se encuentra compuesto básicamente por normas o reglas, que responden a diferentes elaboraciones, normas que pueden ser observadas tanto en forma estática como dinámica, siempre producidas por el hombre. ${ }^{16}$

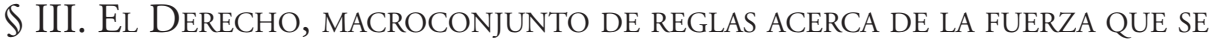 EXPRESA POR INTERMEDIO DE REGLAS PRIMARIAS Y SECUNDARIAS}

No se puede demostrar, porque la realidad lo desborda, que el rasgo principal del Derecho sea que sus reglas estén garantizadas o protegidas por la fuerza. Todo indica que es más segura la afirmación que sostiene que la verdadera posición es que el Derecho consiste principalmente en reglas acerca de la fuerza. Reglas que configuran pautas para el ejercicio de la fuerza. El Derecho, entendido como sistema, es un macroconjunto de reglas sobre la organización y aplicación de la fuerza, cuya representación o expresión se concretiza por intermedio del discurso generado por el poder estatal. El término Derecho, empleado para denotar la organización y aplicación de ese fenómeno que es la misma fuerza estatal, es sinónimo de enunciados que se integran en un sistema normativo. Estas disposi-

\footnotetext{
${ }^{15}$ Guastini, Riccardo, Distinguiendo, Gedisa, Barcelona, 1999, p. 352.

${ }^{16}$ Mario Bunge enseña que el más simple de los análisis del concepto de sistema incluye los conceptos de composición, entorno, estructura y mecanismo. La composición de un sistema es la colección de sus partes; el entorno del sistema es la colección de las cosas que actúan sobre sus componentes, o a la inversa; la estructura de un sistema es la colección de las relaciones, en particular de vínculos y enlaces entre los componentes del mismo, así como entre éstos y los componentes del entorno; por último, el mecanismo de un sistema está compuesto por los procesos internos que lo hacen funcionar, es decir, cambiar en algunos aspectos, mientras que conserva otros. (V. Bunge, Mario, Emergencia y convergencia, Gedisa, Barcelona, 2004, pp. 25-60, y Filosofía y Sociedad, Siglo XXI editores, México, D.F., 2008, pp. 9-48).
} 
ciones o enunciados tienen algo en común: ser reglas que pretenden llevar a cabo la regulación de la fuerza estatal.

Sin embargo, no puede pasarse por alto la cuestión de que el Derecho no es un instrumento neutral porque siempre su normativa y aplicación viene precedida de presupuestos filosóficos e ideológicos. Por dicha razón, suele decirse que el Derecho es un instrumento para el control social. Debe añadirse que las reglas de comportamiento en que el Derecho consiste también son una herramienta de la que se sirve racionalmente el hombre para disponer la coexistencia.

Por lo pronto, el Derecho se integra con la totalidad del discurso jurídico positivo vigente en un Estado. Se edifica gradual y escalonadamente con el lenguaje prescriptivo producido por los poderes del Estado. ${ }^{17}$

En líneas generales, los poderes del Estado que tienen aptitud para generar este discurso prescriptivo son: (a) los poderes constituyentes (sean éstos originarios o derivados) y (b) los poderes constituidos. El poder constituyente originario es el que da nacimiento a la primera constitución o ley mayor estatal, norma jurídica prescriptiva que programa la arquitectura y control de las funciones de los poderes del Estado y confiere estatus a los derechos fundamentales de las personas o grupos de ellas. Se trata del lenguaje prescriptivo por excelencia, en razón de que todo el resto de las disposiciones subconstitucionales del sistema jurídico, al fundar su validez en la Ley Mayor, pueden ser consideradas, en forma rudimentaria, como derivaciones o apéndices del discurso prescriptivo constitucional.

El Derecho puede ser visto y entendido, pues, como un hecho social, cuyo discurso instrumenta la arquitectura social, dando contenido a las pautas que requiere la organización y aplicación de la fuerza estatal que disponga llevarla a cabo. A partir de tal lectura de ese fenómeno complejo que configuran los sistemas jurídicos, sus propiedades más relevantes consisten en normas y prácticas prescriptivas.

Fundamentalmente por razones didácticas ${ }^{18}$, puede distinguirse que el sistema jurídico está integrado, al menos, por dos clases de las siguientes normas, en orden

\footnotetext{
${ }^{17}$ Bobbio señala, en su célebre trabajo "Ciencia del Derecho y Análisis del Lenguaje”, que la jurisprudencia es el análisis científico del discurso del legislador o lenguaje de las leyes. El trabajo se encuentra en Contribución a la Teoría del Derecho, Torres Editor, Valencia, 1980, pp. 186 y ss.

${ }^{18}$ El empleo de normas primarias y normas secundarias utilizado por el saber jurídico revela distinciones importantes entre las diferentes fuentes. Además, el criterio de demarcación entre normas primarias y secundarias puede responder a una ponderación axiológica, a una cuestión cronológica o a un aspecto funcional. Se toma partido por el aspecto funcional, aunque apréciese que, en rigor, no puede descuidarse el hecho de que las normas "que confieren estatus" a los derechos fundamentales también se dirigen a los funcionarios, porque éstos son también ciudadanos y porque como servidores públicos deberían realizar su observancia ajustada. A su turno, las reglas aquí denominadas secundarias también rozan la actividad del ciudadano,
} 
a la función que cumplen y los destinatarios a quienes se dirigen ${ }^{19}$ : (a) primarias, que son las que prescriben facultades, obligaciones o prohibiciones a las personas, y (b) las normas secundarias, que son las que confieren potestades a los funcionarios o estipulan sanciones o reglan el cambio intrasistémico. También existen "enunciados que no son normativos, pero que influyen en los efectos normativos de otros enunciados"20; se cita, como ejemplo, el preámbulo de la Constitución federal de la Argentina: “...con el objeto de constituir la unión nacional, afianzar la justicia, consolidar la paz interior, proveer a la defensa común, promover el bienestar general, y asegurar los beneficios de la libertad..." Seis reglas básicas de la ordenación comunitaria.

En su obra Sobre el Derecho y la Justicia, publicada en 1958, Alf Ross, al preguntarse cómo se distingue el contenido de un ordenamiento jurídico nacional de otros cuerpos individuales de normas, tales como las del ajedrez o las de cortesía, sostuvo que un orden jurídico es un cuerpo integrado por reglas que determinan las condiciones bajo las cuales debe ejercerse la fuerza física contra una persona; el orden jurídico nacional establece un aparato de autoridades públicas (los tribunales y los órganos ejecutivos) cuya función es ordenar y llevar a cabo el ejercicio de la fuerza en casos específicos. $\mathrm{O}$, más brevemente, un orden jurídico nacional es el conjunto de reglas para el establecimiento y funcionamiento del aparato de fuerza del Estado ${ }^{21}$. Dentro de ese orden jurídico, Ross aceptó que las normas podían ser divididas o clasificadas en dos grupos, según su contenido inmediato: normas de conducta (quedarían dentro del campo que en esta pieza se denominan normas primarias) y normas de competencia (poder, autoridad). Las primeras prescriben una línea de acción, mientras que las segundas crean una competencia o autoridad ${ }^{22}$.

Ross criticó el punto de vista que establecía que el Derecho se encontraba constituido por reglas respaldadas por la fuerza. Además, hizo explícito que la

ya que en el Estado constitucional la organización del perímetro del poder es una instancia reglada. Por lo demás, en la teoría de Hans Kelsen, las verdaderas normas jurídicas serían las denominadas aquí secundarias, aunque, en rigor, deberían ser llamadas primarias porque serían las únicas o relevantes normas del sistema. Realizada esta justificación, pues, se mantiene la distinción con los fines y orientación indicada en el texto principal, más arriba.

${ }^{19}$ Bоввіо, Norberto, Contribución a la Teoría..., ob. cit., p. 317.

${ }^{20}$ Alchourrón, Carlos E. y BulYgin, Eugenio, Introducción a la metodología de las ciencias jurídicas y sociales, $3^{a}$ reimpresión, Astrea, Buenos Aires, 1998, pp. 106-108.

${ }^{21}$ Ross, Alf, Sobre el Derecho y la Justicia, traducción de Genaro Carrió, Eudeba, Buenos Aires, 1994, p. 34 .

${ }^{22}$ Ross, Alf, ob. cit., p. 32. 
relación entre las normas jurídicas y la fuerza consiste en el hecho de que ellas se refieren a la aplicación de ésta, y no en el hecho de que estén respaldadas por el uso de la fuerza. Rechazó, por lo tanto, que las normas de competencia (quedarían dentro del ámbito que en esta contribución se denominan normas secundarias) fuesen las únicas que constituyen el ordenamiento jurídico.

Además, Ross afirmó que el Derecho puede ser caracterizado por dos notas: (a) que consiste en reglas concernientes al ejercicio de la fuerza, y (b) que consiste en normas de conducta y de competencia. ${ }^{23}$

Consiguientemente, norma primaria y norma secundaria en este contexto se encuentran combinadas por una relación de naturaleza funcional. Desde este enfoque, se aduce que el que tiene naturaleza prescriptiva es el sistema considerado en forma global y que no cabe predicar sino la juridicidad como propiedad del sistema normativo contemplado integral y conjuntamente, y no de la norma considerada de modo aislado.

No hay mayores dificultades para reconocer que la coercibilidad es una propiedad del sistema jurídico, y no de la norma reputada de modo aislado.

Sin embargo, Hans Kelsen, el más distinguido e influyente jurista del siglo XX, en su obra Problemas capitales de la teoría jurídica del Estado, desarrollados con base en la doctrina de la proposición jurídica, publicada en 1911, observó que la esencia de la norma jurídica con respecto a los sujetos del Derecho consiste en que los obliga; los diferentes deberes jurídicos de los súbditos de los órganos del Estado, o del Estado mismo, son creación del orden jurídico, que no es sino la suma de las normas del Derecho ${ }^{24}$. Por su imperatividad, es decir, por su naturaleza eminentemente sancionatoria, sólo las aquí denominadas normas secundarias formarían parte -en verdad- del sistema jurídico.

Kelsen, años más tarde, en 1960, en la segunda edición de la Teoría pura del Derecho, atenuó un poco la posición al distinguir entre normas jurídicas independientes y no independientes: "...de lo dicho resulta que un orden jurídico, aunque de ninguna manera todas sus normas estatuyan actos coactivos, puede con todo ser caracterizado como un orden coactivo, en cuanto todas las normas que de por si no estatuyen actos coactivos, y que, por tanto, no imponen obligaciones, sino que sólo facultan o permiten positivamente la producción de normas, son normas no independientes que sólo valen en conexión con una norma que estatuye un acto coactivo... ${ }^{25}$.

\footnotetext{
${ }^{23}$ Ross, Alf, ob. cit., pp. 57 y ss.

${ }^{24}$ Kelsen, Hans, Problemas capitales de la teoría jurídica del Estado, desarrollados con base en la doctrina de la proposición jurídica, traducción de la 2a ed. del alemán de Wenceslao Roces, Porrúa, México, 1987, p. 271.

${ }^{25}$ Kelsen, Hans, Teoría pura del Derecho, traducción de Roberto Vernengo, 2a ed., Porrúa, México, p. 70.
} 
Nótese que si se aceptase que en rigor son las normas secundarias las únicas que integran un sistema jurídico estatal, resulta interesante describir alguna consecuencia de este esquema teórico de raíz "kelseniana", o llevarlo hasta sus últimas consecuencias, poniendo un ejemplo. Tal proposición se podría expresar del siguiente modo: todos los enunciados jurídicos que integran un ordenamiento y que reglamentan el derecho individual y colectivo del trabajo, o de enseñar y aprender, o de libertad de expresión, etcétera $(v$ gr.: las reglas primarias o de conducta contenidas en los arts. 14 bis $^{26}$ y $14^{27}$, respectivamente, de la Constitución federal de la Argentina), y en tanto no establezcan sanciones -son normas no independientes-, sólo recibirán su carácter de jurídico en conexión con otras normas del sistema que estatuyan sanciones o actos coactivos respecto de las líneas de acción estipuladas por aquéllas.

En realidad, y tal como se analiza más adelante, el problema de este esquema no es la insatisfacción que provoca. Por ahora, sólo adelanto el ejemplo. Y su crítica: es incorrecto decir -actualmente- que las reglas constitucionales que confieren el reconocimiento de los derechos fundamentales no sean normas que impongan líneas de acción a los poderes estatales. Y, por ende, que no sea factible decidir el índice o grado de coactividad que ellas tienen.

\section{\$IV. EsTADO CONSTITUCIONAL}

Rasgo dominante del Estado constitucional consiste en que la coexistencia de los hombres es regulada por el Derecho. Para el ciudadano, el orden jurídico se

\footnotetext{
${ }^{26}$ Art. 14 bis. El trabajo en sus diversas formas gozará de la protección de las leyes, las que asegurarán al trabajador: condiciones dignas y equitativas de labor; jornada limitada; descanso y vacaciones pagados; retribución justa; salario mínimo vital móvil; igual remuneración por igual tarea; participación en las ganancias de las empresas, con control de la producción y colaboración en la dirección; protección contra el despido arbitrario; estabilidad del empleado público; organización sindical libre y democrática, reconocida por la simple inscripción en un registro especial.

Queda garantizado a los gremios: concertar convenios colectivos de trabajo; recurrir a la conciliación y al arbitraje; el derecho de huelga. Los representantes gremiales gozarán de las garantías necesarias para el cumplimiento de su gestión sindical y las relacionadas con la estabilidad de su empleo.

El Estado otorgará los beneficios de la seguridad social, que tendrá carácter de integral e irrenunciable. En especial, la ley establecerá: el seguro social obligatorio, que estará a cargo de entidades nacionales o provinciales con autonomía financiera y económica, administradas por los interesados con participación del Estado, sin que pueda existir superposición de aportes; jubilaciones y pensiones móviles; la protección integral de la familia; la defensa del bien de familia; la compensación económica familiar y el acceso a una vivienda digna.

${ }^{27}$ Art. 14. Todos los habitantes de la Nación gozan de los siguientes derechos conforme a las leyes que reglamenten su ejercicio; a saber: de trabajar y ejercer toda industria lícita; de navegar y comerciar; de peticionar a las autoridades; de entrar, permanecer, transitar y salir del territorio argentino; de publicar sus ideas por la prensa sin censura previa; de usar y disponer de su propiedad; de asociarse con fines útiles; de profesar libremente su culto; de enseñar y aprender.
} 
presenta como conjunto de reglas que determinan las condiciones en que ha de comportarse con relación a los demás.

La gran mayoría de las doctrinas iuspositivistas suele admitir que las dos diferencias que marcan la distinción entre los sistemas jurídicos con los morales, religiosos o de trato social consisten en que: (a) los sistemas jurídicos, para el caso que no se cumpla la conducta reglada, estipulan la aplicación de sanciones de carácter externo, que en última instancia puede derivar en la utilización de la fuerza física, y (b) el monopolio de la coacción se encuentra en manos del Estado, es decir, se encuentra institucionalizada.

Si se considera que la coactividad es un elemento central de los sistemas jurídicos, razonablemente es dable entender que se presuponen los siguientes datos: (a) que sólo el Derecho puede limitar al poder, pero que sólo el poder crea al Derecho; (b) que el Estado, entendido como organización social que monopoliza el ejercicio de la fuerza, es también quien monopoliza la producción jurídica y su aplicación ${ }^{28}$. La fuerza o coacción que es monopolizada por el Estado es el rasgo caracterizador de los sistemas jurídicos considerados globalmente, como conjunto de normas primarias y secundarias, y no una calificación aislada de uno o más enunciados que componen el sistema, que pueden ser no prescriptivos. Así, la fuerza se ubica en la génesis del Derecho y en su aplicación.

Sin embargo, queda una importante cuestión por analizar. En efecto, el Estado, que es el que crea el Derecho, puede ser visto con relación a éste, al mismo tiempo, de dos modos: como un fin o como un medio.

Veamos.

\section{\ V. ESTADO “FIN"}

Si no se ve al Estado como un medio para la protección de los derechos fundamentales (sencillamente, porque la realidad clausura la posibilidad de que puede concretarse dicho postulado), será difícil argüir en contra de que el Derecho es, y probablemente será, la ley del más fuerte. Lo expuesto no implica que aplicación de la fuerza no pueda ser justa. Lógicamente podría llegar a serlo, no puede descartarse. Quiero señalar que, en este esquema, la fuerza es lo sustantivo, la expresión del más fuerte. La terminología "la ley del más fuerte", de exclusiva prosapia descriptiva, nada tiene que ver con la aprobación o reprobación que con fundamentos éticos o de justicia produzcan ciertos sistemas jurídicos, como adujo Ross $^{29}$. Y será la ley del más fuerte si se entendiere que las normas -aquí llama-

\footnotetext{
${ }^{28}$ Bobbio, Norberto, El futuro de la democracia, Planeta-Agostini, Buenos Aires, 1994, p. 14.

${ }^{29}$ Afirmó Alf Ross: "Se ha sostenido que el sistema de violencia impuesto por Hitler no era un ordenamiento jurídico, y el positivismo jurídico ha sido acusado de traición moral por su reconocimiento no crítico de
} 
das "secundarias" - son las verdaderas normas del sistema jurídico (Kelsen), o las únicas capaces de conferirle juridicidad, por cuanto ellas, y sólo ellas, son las que peculiarmente estipulan sanciones o confieren potestades para hacerlo, dado que allí -se arguye- el rasgo de la fuerza o coacción constituye el contenido mismo de la reglamentación que realiza el Derecho.

Pienso que para estas corrientes el Derecho bien podría ser caracterizado como la razón de la fuerza, expresión cuyo contenido, dicho sea de paso, cuenta con altísimas probabilidades de corroboración empírica en la realidad mundial. Conviene distinguir, con la mayor claridad posible, qué se intenta decir cuando se afirma que "el Derecho es la razón de la fuerza". Se quiere subrayar que, precisamente, esta regulación de la coacción que despliega el Derecho es lo que lo distingue o separa de otros sistemas u órdenes normativos, como pueden ser, por ejemplo, la moral o la religión.

Es posible advertir, además, que en esta perspectiva teórica que permite calificar al Derecho como la razón de la fuerza, la palabra "razón" es usada en un sentido muy débil como "orden y método en alguna cosa", a lo que debe asociarse la idea, o va implícita, de que los principios y reglas que integran un sistema jurídico pueden ser impuestos, aun coactivamente ${ }^{30}$. Significa que en determinadas situaciones se puede constreñir por la fuerza, incluida la violencia física contra $\mathrm{la} / \mathrm{s}$ persona/s, para el cumplimiento de determinadas prescripciones del sistema jurídico. Tampoco va en contra o en detrimento de la coercibilidad, como nota dominante de los sistemas jurídicos, que en múltiples ocasiones el Derecho sea efectivo de modo espontáneo, sin necesidad de tener que recurrir a la utilización de la fuerza estatal.

En este contexto que se analiza, el uso de "razón" podría ser entendido y distinguido en una variedad de planos, de los que, por su importancia, seleccionaré dos: el epistemológico y el normativo.

(i) Dentro del campo de la opción epistemológica referida, afirmar que el Derecho es la "razón de la fuerza" significaría, sencillamente, decir que la razón es una guía autónoma del hombre en todos los campos en que es posible una indagación o una investigación. En este sentido, se dice que la "razón" es una facultad propia del Hombre y que lo distingue de otros animales ${ }^{31}$. En este marco, el término

que tal orden no era Derecho. Pero una terminología descriptiva nada tiene que hacer con la aprobación o reprobación moral. Puedo considerar a cierto orden como un orden jurídico, y al mismo tiempo entender que mi deber moral más alto es derrocarlo" (V. Sobre el Derecho y la justicia, ob. cit., p. 32).

${ }^{30}$ Díaz, Elías, Curso de Filosofía del Derecho, Marcial Pons, Madrid, 1998, p. 78.

${ }^{31}$ Abbagnano, Nicola, Diccionario de filosofía, Fondo de Cultura Económica, México, 1996, p. 978. 
"razón" significa "facultad de pensar", y no que el hombre siempre piensa. Puede hacerlo. Nada más.

"Razón", empleada en este contexto, quiere poner de manifiesto sólo que la aplicación de la fuerza estatal es precedida habitualmente por un criterio cognitivo.

(ii) En el ámbito normativo, el empleo de la palabra "razón” puede significar tanto como: (a) anoticiar, informar de un asunto; (b) aludir a la facultad de discurrir, y a las palabras o frases con que se expresa el discurso; (c) o, más concretamente, referir al discurso de los poderes del Estado que reglamenta o regula el momento, la forma, el sujeto y la dosificación o quantum para el empleo de la fuerza estatal. No queda comprendido en dicho ámbito de significación el "qué" o "sustancia" de que puede o debe, o no puede o no debe, disponer la reglamentación coactivamente.

(iii) En un sentido débil, el "Derecho como la razón de la fuerza" -expresión que no es más que una categoría que empleo para calificar la visualización genérica que del fenómeno jurídico hacen o realizan importantes corrientes pertenecientes a la familia del positivismo jurídico-quiere decir tanto: (a) que la fuerza que los hombres aplican a través del Estado, a diferencia de la fuerza existente en el resto del mundo animal, es organizada y empleada sobre la base de criterios que, genéricamente, pueden ser descriptos como la capacidad de entender o comprender qué tienen aquéllos, es decir, basados en su inteligencia, y (b) que la fuerza es organizada y aplicada por intermedio del discurso, cuya normatividad es la nota peculiar con que se expresa el Derecho.

\section{\$ VI. ESTADO “MEDIO”}

$\mathrm{Si}$, en cambio, al Estado se lo considera un instrumento, el ente únicamente se legitima si tutela y satisface los derechos fundamentales. Es más: aquí el Estado no sólo es el que confiere los derechos fundamentales, sino que además debe generar las condiciones para su realización, ya sea por abstención o por prestación. En este caso, a diferencia del anterior, el Estado debe legitimarse mediante la procreación y respeto del ambiente necesario para la realización de los derechos fundamentales.

Para comprender cabalmente esta posición, conviene tener en cuenta la observación que realiza al respecto Luigi Ferrajoli al aseverar que actualmente hay un nuevo paradigma en la historia de la cultura jurídica. Ferrajoli afirma que gran parte de los valores de justicia elaborados por la doctrina iusnaturalista de los siglos XVII y XVIII (valor de la persona humana, igualdad, derechos civiles y políticos) han sido consagrados en las modernas constituciones en forma de principios 
normativos fundamentales que contienen limitaciones cuyo destinatario es el poder público. ${ }^{32}$

Los derechos fundamentales son Derecho positivo por cuanto están estipulados en las constituciones -igualdad, de los derechos de libertad a los derechos sociales-y son, en esta clave de interpretación, Derecho sobre derechos. Es decir, las reglas de los derechos fundamentales disciplinan en cierta medida la programación del contenido de toda la legislación subconstitucional, y no solamente la programación de la forma de producción a través de normas de procedimiento sobre la formación de leyes, que fue y es un paradigma del positivismo clásico. En este esquema de pensamiento, los derechos fundamentales se afirman siempre como leyes del más débil en alternativa a la ley del más fuerte que regía y regiría en su ausencia. ${ }^{33}$

\section{§ VII. EL POSITIVISMO JURÍDICO Y LA CARACTERIZACIÓN DEL DEREChO COMO "LA RAZÓN DE la FUerza”}

En la literatura jurídica frecuentemente se polemiza alrededor de las propiedades que distinguen a los sistemas jurídicos de otros sistemas normativos, como la religión, la moral o las reglas deportivas. El ideario, cuyo contorno luce "que el Derecho es algo distinto, definitivamente diferente de otros órdenes normativos", es producto del positivismo jurídico, entendido como corriente teórica y con generosísima amplitud; donde el fenómeno jurídico se distingue de otros fenómenos normativos porque el Derecho es la organización e institucionalización de la coerción y no se encuentra vinculado o necesariamente dependa de la moral, aunque eventualmente podrían coincidir.

Las teorías positivistas - hijas de la aspiración muy humana de intentar la estipulación de cierto grado de certidumbre para (y en) sus relaciones- tienen argumentos más plausibles para insistir en pretender definir al Derecho como el sistema jurídico cuyas reglas sean la razón de la fuerza. Lo expuesto no implica una adhesión incondicional a las teorías iuspositivistas, sino, sencillamente, la simple comprobación empírica de que, en su inmensa mayoría, los sistemas jurídicos estatales existentes en el mundo se hallan estructurados por el Derecho que "es" -valga la redundancia- y no por el que "debiera ser", que sí permitiera la cabal realización de los derechos fundamentales, y, con seguridad, sistemas jurídicos tanto más correctos.

${ }^{32}$ Ferrajoli, Luigi, Derecho y razón. Teoría del garantismo penal, Trotta, Madrid, 1997, pp. 218, 355, 356, 357 y 854.

${ }^{33}$ Ferrajoli, Luigi, Derechos y Garantías. La ley del más débil, Trotta, Madrid, 1999, pp. 53 y ss. 
Un simple ejercicio permite comprobar que el Derecho, como instrumento para el control y la arquitectura social, no ha podido existir sin la fuerza. Hasta el siglo Xx, el Derecho, descripto como se lo intenta hacer en esta disertación, ha encarnado siempre con mayor o menor dureza la posición del más fuerte, donde el más fuerte es el poder. Hace tres siglos y medio, Thomas Hobbes replicó a sir E.Coke que no es la verdad, sino la autoridad, la que hace el Derecho:

"La razón de nuestro estado, nuestro hombre artificial, es lo que constituye la ley, y no la jurisprudencia o sabiduría de los jueces subordinados... y la ley es una orden... y una orden es la manifestación de voluntad de quien manda." 34 .

De lo expuesto en párrafos precedentes, claramente se advierte que en la afirmación "el Derecho ha sido y es la razón de la fuerza para desarrollar la arquitectura y ejercer el control social”, el término "razón” no significa “justo o correcto”. Razón es utilizada, solamente, como actitud cognitiva y descriptiva de la reglamentación de la fuerza estatal que lleva a cabo el sistema jurídico.

Llegado este punto, vale la pena preguntarse: (a) ¿puede tener alguna incidencia la constitución escrita en todo este asunto?, y (b) y si fuera cierto, ¿`cuál es el lugar exacto que ocupa la constitución escrita del Estado en toda esta cuestión?

\section{$\S$ VIII. LA BASE DE LOS SISTEMAS JURÍDICOS ESTATALES}

"Constitución" significa una categoría jurídica básica de la teoría y práctica del Derecho. Los modernos sistemas jurídicos estatales son sistemas normativos estructurados jerárquicamente. En su base se encuentra la norma constitucional, que a su vez implica propiamente un "subsistema normativo". La estructura jerárquica del sistema jurídico de un Estado puede expresarse de modo rudimentario, como sostiene Kelsen, en los siguientes términos: supuesta la existencia de la norma fundamental, la constitución representa el nivel más alto dentro del derecho estatal. ${ }^{35}$

La palabra "constitución" es usada en el lenguaje jurídico, político y social con una pluralidad de significados. No es éste el sitio para llevar a cabo un listado de significaciones ${ }^{36}$. Sí, en cambio, pretendo describir en qué sentido puede enten-

\footnotetext{
${ }^{34}$ Hobbes, Thomas, Leviatán, Fondo de Cultura Económica, Buenos Aires, 1992, p. 222.

${ }^{35}$ Kelsen, Hans, Teoría General del Derecho y del Estado, traducción de Eduardo García Maynez, Imprenta Universitaria, México, 1958, p. 146.

${ }^{36}$ V. Comanducci, Paolo: "Modelos e interpretación de la constitución", traducción de Manuel Ferrer Muñoz, en AA.VV.: Teoría de la Constitución. Ensayos escogidos, Manuel Carbonell, compilador, México, Porrúa, 2008, pp. 124-154.
} 
derse que la "constitución" escrita es la base del sistema jurídico estatal, y cuáles son las jerarquías que tiene la norma constitucional con el resto de las normas que lo integran, y si de ello es a su vez derivable alguna proposición peculiar. Para tal cometido, será suficiente, por el momento, ensayar las siguientes orientaciones, las que se encuentran dirigidas a las constituciones que observan cierto grado de rigidez, entendiendo por rigidez que la norma constitucional no puede ser reformada mediante la utilización de los mismos procesos estipulados para la configuración de la legislación ordinaria de rango subconstitucional.

Veamos.

Descriptiva y objetivamente, suele emplearse el término "constitución" para designar un conjunto de reglas que singularizan, personifican e identifican a los sistemas jurídicos estatales, expresadas en un documento y que en relación a todas las demás reglas del sistema son fundamentales. Al afirmarse que "la constitución es la norma de mayor jerarquía del sistema jurídico", ¿qué se postula exactamente? Se puede hablar de jerarquía lógico-normativa y de jerarquía axiológica ${ }^{37}$. Me ocuparé de la primera: la constitución resulta formalmente superior a las normas cuya producción programa, ya que la constitución es lógicamente anterior o viene predispuesta con relación a las normas infraconstitucionales.

La constitución es la norma mayor del sistema jurídico como consecuencia de una decisión positiva del poder estatal. Si la constitución es la norma de mayor jerarquía del sistema, no es lógicamente posible ir de la norma superior a la norma inferior sin dejar de atravesar la distancia jerárquica que hay entre ellas. Negar esta distancia sería contradictorio, porque no puede irse de lo superior a lo inferior sin atravesar las distancias que los separan. Este sencillo ejemplo demuestra la jerarquía lógica de la constitución. Contrariamente, no hace falta decirlo, implica una contradicción.

En este campo, la constitución es el plan maestro que esquematiza las formas y procedimientos que debe observar toda la producción jurídica de los poderes del Estado. No caben dudas de que es concretamente en esta relación de jerarquía lógica-estructural entre la constitución y el resto de las normas del sistema jurídico, donde puede afirmarse que la constitución disciplina y programa la configuración del cuándo, el cómo, el quién y el cuánto del ejercicio del poder coactivo.

\footnotetext{
${ }^{37}$ Cuando se predica que "la Constitución es la norma jurídica de mayor jerarquía del ordenamiento jurídico", el enunciado debe ser entendido como que la norma ocupa la base del sistema normativo por obra de las fuentes de producción jurídica estatal. El derecho internacional de los derechos humanos y/o el derecho comunitario o de integración regional que en algunos Estados tiene jerarquía normativa constitucional, o más aún, hasta puede ser que tenga supremacía respecto del propio texto constitucional, no ocupa en esta oportunidad un sitio para las indagaciones, no porque carezca de importancia la temática-todo lo contrario-, sino porque el examen se ciñe al Derecho producido exclusivamente por fuente estatal.
} 
La constitución determina regiamente la producción de reglas jurídicas de alcance general; por consecuencia, regula la forma y, hasta cierto nivel, el contenido de la elaboración estatal.

Si el Derecho es la "razón de la fuerza" -en el sentido expuesto ut supra sección III-, la constitución sería el paradigma de esta tecnología. Claro que convenir ello traería como corolario admitir que las normas de conducta (normas primarias) escritas en los textos constitucionales son, a lo sumo, indicadores o menús, pero carentes de fuerza normativa e incapaces de conferir juridicidad al sistema normativo, ya que en estos enfoques normativistas la juridicidad del sistema es propuesta por sus normas secundarias. En este esquema, por lo tanto, es evidente que no todas las reglas constitucionales tendrían la misma relación de supraordenamiento y jerarquía con el resto de las normas del sistema jurídico. Sólo son fundamentales y supremas: las que determinan las formas y sistema de Estado y de gobierno, respectivamente, y las que disciplinan la producción y el conferimiento de las potestades legislativa, administrativa y jurisdiccional a los órganos que encarnan la voluntad estatal.

\section{\$ IX. DeRechos Fundamentales: LÍNEAS de ACCiÓN} PARA EL EJERCICIO DE LA FUERZA ESTATAL

Distinguir si el Derecho es la razón de la fuerza, es decir, ha sido (y es) la "expresión de los más fuertes" 38 , o en cambio, el Derecho es también la razón de la fuerza pero ahora en sentido fuerte -donde ciertos ideales puedan justificar o no la coactividad del Derecho-, conduce, una vez más, a enfrentar el antiguo y reiteradamente difundido dilema sobre el papel de la ciencia o saber jurídico.

Optar por la segunda de las alternativas supone dejar parcialmente a la sombra algunas ideas de Kelsen con relación a las normas imperativas y, al mismo tiempo, advertir con objetividad el innegable rol que desempeñan los derechos fundamentales en los sistemas jurídicos ${ }^{39}$. El repertorio de los derechos fundamentales que componen todas las constituciones modernas significa una demarcación trascendental para la tarea estatal.

No parece acertado afirmar que la fuerza del sistema jurídico se reduce a la coactividad que emana de las denominadas normas secundarias del sistema. En

\footnotetext{
${ }^{38}$ Boвbio, Norberto, Teoría General..., ob. cit., p. 174.

${ }^{39}$ Elías Díaz plantea que la relación de fuerza-razón en forma de conjunción copulativa -y no en términos más bien disyuntivos, contradictorios o conflictivos- quizá conduzca a una nueva conceptualización del Derecho. La inevitable razón de la fuerza puede y debe ser siempre enjuiciada y controlada desde aquella a la que todos llamamos la fuerza de la razón (ob. cit., p. 78).
} 
efecto, en los sistemas jurídicos que en la base de su escalonamiento jerárquico hospedan a los derechos fundamentales -cuyo estatus es conferido por la constitución-, difícilmente pueda abrigarse duda alguna de que los mismos serían verdaderas "líneas de acción", en el sentido que adjudicó Ross a las normas de conducta (ver ut supra sección III). Que las normas de competencia o de organización del poder, o secundarias, confieren potestades para sancionar y cambiar, no caben dudas. Pero las normas primarias también tienen que ver con la reglamentación de la fuerza, en virtud de que normalmente en ellas se encuentran encastrados los catálogos de derechos fundamentales y sus garantías.

En esta clase de sistemas jurídicos, los derechos fundamentales y sus garantías proveerían el contenido para el uso de la fuerza, configurando directivas para su organización y consecuente aplicación ${ }^{40}$. Como enseñó en nuestra dogmática Germán Bidart Campos, cuando la constitución configura derechos y les da constancia normativa, no lo hace para cumplir un propósito decorativo y literario de pura retórica o alarde léxico, sino para que las personas dispongan de acceso a su goce y a su disfrute, y para que puedan hacerlos valer jurídicamente ante un Estado al que, en reciprocidad, se le demarcan límites, y se le reparte el poder con funciones a cargo de órganos separados, sujetos a control. ${ }^{41}$

Hay constituciones que, en tanto fundamento de validez de los sistemas jurídicos, no se limitan a programar un conjunto de procedimientos dirigidos a posibilitar la planificación y despliegue de la coerción a cargo de los poderes constituidos, sino que además, y aceptando que ellas no son fines sino medios, reputan que los derechos fundamentales en ellas insertados realizan una reglamentación que se considera el ámbito básico de la vida comunitaria en libertad, donde se les concibe no sólo como derechos subjetivos, sino también como reglas objetivas del sistema y, como tales, formal y no materialmente, líneas de acción que deben asegurar un uso correcto de la fuerza estatal. Proposición que implica la compren-

\footnotetext{
${ }^{40}$ La técnica garantista consiste - para Ferrajoli- en incluir valores bajo la forma de límites o deberes en los niveles más altos del ordenamiento jurídico -en nuestro caso, la Constitución- a fin de excluirlos en forma de poderes en los niveles más bajos, convirtiendo en valorativos los juicios de validez sobre las normas de nivel más bajo en relación con las normas que están llamados a aplicar. Si en los niveles más altos no fueran incorporados valores, sino sólo el principio formal que es válido además de vigente quod principi placuit, el juicio de validez se reduciría a una aserción empírica, verificable y cierta, sobre la fuente y los procedimientos previstos para la vigencia de la ley; y las valoraciones, en tal caso, tendrían entrada libre tanto en el lenguaje de las leyes, no vinculadas a la estricta legalidad, como en el de los jueces, no vinculadas a la estricta jurisdiccionalidad y válidamente investidas de poder de disposición en la calificación legal, pero no en la censura de las leyes (Ferrajoli, Luigi, Derecho y Razón, ob. cit., p. 877).

${ }^{41}$ Bidart Campos, Germán J., El Derecho de la Constitución y su fuerza normativa, Ediar, Buenos Aires, 1995 , p. 26
} 
sión global de las complejidades que muestran las realidades configuradas por esos órdenes. No apareja el abandono de la proposición que señala que la actividad dogmática jurídica consiste en describir el estado de cosas que el Derecho configura y determina. Naturalmente, esta demarcación o determinación jamás puede ser completa. Resulta casi imposible que la constitución pueda determinar todas las orientaciones de su realización. En el Estado constitucional la eliminación radical del ámbito de la discrecionalidad es insuperable; la discrecionalidad es un rasgo dominante de la especie humana.

El sistema jurídico constitucional alemán contiene una disposición que ejemplifica normativamente -la proposición que en esta disertación se discute- de manera muy aproximada la tesis que aquí se describe. Dispone el art. $1^{\circ}$, inc. $3^{\circ}$, de la Ley Fundamental de Bonn de 1949 que los derechos fundamentales vinculan a los poderes legislativo, ejecutivo y judicial a título de derecho directamente aplicable. En esta tipología de sistema jurídico la verdadera razón del mismo también residiría en la fuerza normativa de sus derechos fundamentales.

En el caso de la República Argentina, en la actualidad su orden estatal se encuentra instituido por su Derecho constitucional, creación humana que emana básicamente de las reglas generales contenidas en la Constitución federal de 1853 con sus reformas de 1860 -"la constitución histórica"-, 1866, 1898, 1957 y 1994, y en las reglas del Derecho internacional de los derechos humanos que gozan de jerarquía constitucional. La primacía del Derecho internacional de los Derechos Humanos -en adelante DDHH- puede ser observada como un paradigma del Derecho constitucional de la Argentina. Constituyen significativas líneas para la acción estatal y ciudadana. ${ }^{42}$

\footnotetext{
${ }^{42}$ Por intermedio de la reforma constitucional de 1994 se dispuso en el art. 75, inc. 220: “...Corresponde al Congreso... inciso 220: Aprobar o desechar tratados concluidos con las demás naciones y con las organizaciones internacionales y los concordatos con la Santa Sede. Los tratados y concordatos tienen jerarquía superior a las leyes. La Declaración Americana de los Derechos y Deberes del Hombre; la Declaración Universal de Derechos Humanos; la Convención Americana sobre Derechos Humanos; el Pacto Internacional de Derechos Económicos, Sociales y Culturales; el Pacto Internacional de Derechos Civiles y Políticos y su Protocolo Facultativo; la Convención sobre la Prevención y la Sanción del Delito de Genocidio; la Convención Internacional sobre la Eliminación de todas las Formas de Discriminación Racial; la Convención sobre la Eliminación de todas las Formas de Discriminación contra la Mujer; la Convención contra la Tortura y otros Tratos o Penas Crueles, Inhumanos o Degradantes; la Convención sobre los Derechos del Niño; en las condiciones de su vigencia, tienen jerarquía constitucional, no derogan artículo alguno de la primera parte de esta Constitución y deben entenderse complementarios de los derechos y garantías por ella reconocidos. Sólo podrán ser denunciados, en su caso, por el Poder Ejecutivo nacional, previa aprobación de las dos terceras partes de la totalidad de los miembros de cada Cámara. Los demás tratados y convenciones sobre derechos humanos, luego de ser aprobados por el Congreso, requerirán del voto de las dos terceras partes de la totalidad de los miembros de cada Cámara para gozar de la jerarquía constitucional”.
} 
Ciertamente, conceptos morales han sido desarrollados. Fruto de ese desarrollo, ahora el texto constitucional muestra la positividad. Los principios morales han sido positivizados. Los conceptos morales, al ingresar a la Constitución, que es norma jurídica, son ahora, para el Derecho, conceptos de derecho positivo. Ergo, derecho y moral no deben tener un significado necesariamente coincidente, aunque puede suceder. Por lo pronto, persiste la distinción entre lenguaje moral y lenguaje jurídico. Reconozco, no obstante, que son conceptos altamente indeterminados, pero que observa la distinción entre Derecho y moral, entre el Derecho como es y el Derecho como debería ser, entre la descripción del Derecho y su valoración. ${ }^{43}$

En este contexto la palabra "razón" puede ser empleada para definir al término Derecho como la razón de la fuerza, pero derivándose la posibilidad de que el término pueda ser realizado en un sentido "fuerte" y no tan sólo débilmente.

En la lengua española el término "razón" admite una importante variedad de significados, de los cuales, en esta investigación, se ha seleccionado sólo una duplicidad.

En los apartados anteriores -ver ut supra sección III- se exploran los significados del término, en tanto "razón" es apto para denotar, por ejemplo, tanto inteligencia como anoticiamiento o poder de informar sobre la cosa de que se trata (en nuestro caso, la fuerza estatal). Pero "razón” -según la cuarta acepción del $\mathrm{DRAE}^{44}$ - también puede ser empleado para significar "argumento o demostración que se aduce en apoyo de alguna cosa", donde la argumentación como operación intelectual persigue el convencimiento de que algo es correcto. En este caso, las "razones de derecho constitucional", es decir, los derechos fundamentales normados en las constituciones, operarían como un listado o catálogo orientador de las decisiones políticas fundamentales, permitiendo establecer "qué" manda el poder por intermediación del Derecho, y no sólo quiénes mandan o están autorizados para hacerlo, creando regulaciones y aplicando sanciones.

La Ley No 24.820 -publicada en el Boletín Oficial del 29/5/1997- otorgó jerarquía constitucional a la Convención Interamericana sobre Desaparición Forzada de Personas, aprobada por la XXIV Asamblea General de la OEA, en los términos del art. 75, inc. $22^{\circ}$ de la Constitución federal. La Ley No 25.778, publicada en el BO el 3/9/2003, otorgó jerarquía constitucional a la Convención sobre la Imprescriptibilidad de los Crímenes de Guerra y de los Crímenes de Lesa Humanidad, adoptada por la Asamblea General de la ONU el 26/11/1998 y aprobada por Ley No 24.584 .

Consecuentemente, hoy trece instrumentos del DDHH gozan de jerarquía constitucional.

${ }^{43}$ GuAstini, Ricardo, "Los principios constitucionales en tanto fuente de perplejidad", en AA.VV., Derecho procesal constitucional americano y europeo, tomo I, compilador Víctor Bazán, Abeledo Perrot, Buenos Aires, 2010, p. 190.

${ }^{44}$ DRAE, Espasa Calpe, Madrid, 1992, 21 a ed., p. 1731. 
La Constitución federal de la Argentina, por caso (básicamente: Primera Parte, Capítulo Primero: Declaraciones, derechos y garantías; Capítulo Segundo: Nuevos Derechos y en la Segunda Parte, Título Primero, Sección Primera, Capítulo Cuarto: el art. 75, inc. 22 ya aludido), contiene una descripción de un estado de cosas, es decir, un estado deseado por el legislador constituyente. Ese estado de cosas sólo puede ser vislumbrado racionalmente por el constituyente, a condición de que se trate de un mundo constitucionalmente posible. Si el estado de cosas delineado por el constituyente en la Constitución no es "lógicamente posible" (es decir, no puede ser realizado, sus reglas no satisfacen los estándares del querer racional), se trataría de una descripción originariamente falsa de la realidad, que no coincide ni puede coincidir con el estado de cosas. Con seriedad, entonces, sólo puede ser sustentado el ideal que constituye un diseño de un mundo posible; si no es verdadero, no puede ser querido racionalmente por el poder constituyente. ${ }^{45}$

Mi estrategia básica para defender esta proposición consiste en que, tal como se anunció ut supra I, las proposiciones son enunciados acerca del estado de cosas que determina el Derecho.

Una última precisión de singular relevancia. Debe llamarse la atención sobre la utilización del término "razón" en esta dimensión argumentativa. Y la misma se vincula con el alcance y contenido de "qué" es lo que se manda u ordena a través del Derecho en una democracia constitucional. Una posible respuesta sería que lo que se ordena mandar no puede ser otra cosa que no sea la configuración y perfeccionamiento del subsistema de enunciados normativos de naturaleza primaria, que confieren reconocimiento constitucional a los derechos fundamentales. Claro que, si uno de los cometidos principales de la constitución se perfecciona en la determinación de los derechos fundamentales, en qué medida ellos configuran un "orden o sistema” y de qué modo se explica su desarrollo progresivo y los límites que observa o debería observar el itinerario del mismo, de ningún modo puede quedar indeterminado, siendo dicho cometido uno de los rasgos básicos del sistema teórico que pretenda abordar su comprensión racional.

Para finalizar, se dijo al inicio que se propugna establecer contacto con la afirmación cuyo enunciado es que "el derecho es la razón de la fuerza", entendida la palabra "razón" tanto como descripción de la coacción, como de su argumentación.

La primera proposición ha quedado verificada. La descripción de la realidad, es decir, las tareas informativas acerca de ella, como operación intelectual busca

${ }^{45}$ Von Wright, George Henrik: "Ser y deber ser", en AA.VV., La normatividad del Derecho, compiladores Aulis Aarnio, Ernesto Garzón Valdes y Jyrki Uusitalo, Gedisa, Barcelona, 1997, p. 98. 
el hallazgo de la verdad; en este sentido, es verificable que el Derecho es la razón de la fuerza, circunstancia comprobable tan sólo recurriendo al conocimiento del mundo externo.

La segunda proposición muestra que hay demasiado por hacer a su respecto. La argumentación acerca de la realidad persigue la consecución del convencimiento ajeno. Quien argumente que el Derecho debe ser la razón de la fuerza, estará intentando persuadirnos de que son los derechos fundamentales inscriptos en las constituciones la línea decisiva que programa y da fundamento al ejercicio de la coerción estatal.

Si vuelvo la cuestión al título de este trabajo, y en última instancia, perfilando su cierre, puedo afirmar que el Derecho, entendido como la razón de la fuerza, en sentido "débil", es la legalidad proveniente del sistema jurídico prevaleciente. Y el Derecho, entendido como la razón de la fuerza, en sentido "fuerte", es la argumentación para una renovada realización del sistema jurídico. 